D.E.L.T.A., Vol. 15, N. ${ }^{\circ}$ EsPECIAL, $1999(183-199)$

\title{
ESTUDOS DO TEXTO E DO DISCURSO NO BRASIL
}

(Text and Discourse Studies in Brazil)

\author{
Diana Luz Pessoa de BARros \\ (Universidade de São Paulo - Brasil)
}

ABSTRACT: The paper draws the distinction between Text and Discourse studies and relates the field to the other area of Linguistic studies developed in Brazil, giving special attention to the aproaches taken.

KEY WORDS: Discourse; text; teories; study centers

PaLAVRAS-CHAVE: Discurso; correntes teóricas; centros de estudo

Este artigo organiza-se em duas partes: a primeira, sobre o lugar dos estudos do texto e do discurso entre as teorias da linguagem; a segunda, sobre tais estudos no Brasil.

Para a primeira questão foram retomadas, em grande parte, as reflexões que fiz sobre os estudos do texto e do discurso em conferência proferida como uma das provas de concurso de professor titular na Universidade de São Paulo, publicadas posteriormente na revista Língua e Literatura (1996).

1. Reflexões sobre os estudos do texto e do discurso.

Se os estudos de Saussure, de reconhecida importância para situar a lingüística entre as ciências humanas, para estabelecer seu objeto, limitaram o campo de possível interesse do lingüista, ao separarem rigidamente a lín-gua da fala, o lingüístico do extralingüístico - por má interpretação do mestre, dizem alguns, por necessidade do momento histórico em que se trans-formavam os estudos da linguagem, afirmam outros, ou por razões ideológicas, consideradas as condições de produção do texto de Saussure, insistem terceiros -, os estudos que a partir de então se desenvolveram procuraram de modos diversos preencher os espaços entre as dicotomias estáveis, resgatar, do exílio da fala, outros elementos de interesse do estudioso da linguagem. Em outras palavras, os estudos posteriores reviram e retomaram posições postas de lado pela lingüística saussuriana, alargaram seu campo de estudos, deixaram, enfim, os trilhos previamente assentados, mas mantiveram, com outros nomes e novas definições, a distinção entre o que cabe ao lingüista examinar e o que é da alçada de outras ciências ou disciplinas. Essas mudanças ocorreram sobretudo quando os lingüistas se debruçaram mais seriamente sobre questões 
de significação e sentido.

O caminho, a meu ver, fez-se pela ruptura de duas barreiras: a que impede a passagem da frase ao texto, a que separa o enunciado de sua enunciação. Alguns estudiosos procuraram vencer a primeira bar-reira, outros saltaram a segunda, muitos trataram de derrubar ambos os limites. No primeiro caso, devem ser mencionados os estudos de Harris que, sem fugir dos pressupostos da teoria distribucional, propõe, com método formal e prescindindo do conteúdo, que se examine a estruturação global do texto.

Já as teorias pragmáticas, por exemplo, vão além da segunda barrei-ra, retomam ao extralingüístico elementos situacionais indispensáveis à constituição do sentido do texto e descrevem e explicam os laços que unem enunciação e enunciado. Agrupam-se entre as pragmáticas teorias diferentes que têm, porém, em comum, o fato de procurarem aumentar a "fatia" da linguagem que tradicionalmente cabe aos estudos lingüísticos, pela recuperação de uma parte do "caos" da fala e pela consideração de certas condições de uso da língua. Os fatos pragmáticos ou de interação social do homem na e pela linguagem são definidos, por essas teorias, como fatos de língua ou de competência do falante, isto é, como fenômenos sistemáticos, que fazem parte das regras que o falante domina para usar a língua.

Os estudos do texto e do discurso, por sua vez, caracterizam-se pela ruptura das duas barreiras, ao mesmo tempo: preocupam-se com a organização global do texto e examinam as relações entre discurso, enunciação e fatores sócio-históricos.

Esses caminhos novos trouxeram aos estudos da linguagem mudanças significativas de posicionamento e não somente acrescentamentos: deixou-se de ver a língua como lugar de representação apenas de significados objetivos, para considerá-la como meio convencional de agir no mundo (veja-se a pragmática dos atos de linguagem); passou-se a considerar a linguagem, por natureza, como um instrumento de argumentação e de interação e não somente de informação (vejam-se os estudos de Ducrot, as teorias da argumentação, a sociolinguística interacional ou a análise da conversação); concebeu-se o texto (ou o discurso) e não mais a frase como unidade de sentido, tomando-o como o objeto dos estudos lingüísticos e condicionando a descrição das frases ao exame satisfatório dos mecanismos de organização textual (vejam-se as teorias do texto e do discurso em geral e os escritos precursores de Bakhtin); colocou-se a intersubjetividade como anterior à subjetividade, ou seja, a relação 
entre interlocutores não apenas funda a linguagem e dá sentido ao texto, como também constrói os próprios sujeitos produtores do texto (vejam-se os estudos de Bakhtin, as diversas teorias pragmáticas e a análise da conversação); caracterizou-se o discurso como lugar ao mesmo tempo do social e do individual; definiu-se a linguagem pelo dialogismo em suas duas acepções, a do diálogo entre interlocutores e a do diálogo que cada texto mantém com outros textos.

Essas novas posições criaram um novo objeto (ou mais de um) dos estudos lingüísticos, com as características apontadas: ao mesmo tempo social e individual, instrumento de argumentação e de informação, fundado pela interação ou pelas relações intersubjetivas que antecedem e criam a subjetividade, de dimensão maior que a da frase e com organização própria, constitutivamente dialógico, ou mesmo, duplamente dialógico.

Em síntese, as diferentes teorias pragmáticas, textuais e discursi-vas trazem novas posturas e objeto aos estudos da linguagem, na segunda metade do século XX. E o fazem com fundamentos diferentes, herdados de quadros teóricos diversos, com que dialogam - a lógica e a filosofia da linguagem, a antropologia estrutural, os estudos cognitivos, a psicanálise lacaniana, o materialismo histórico, entre outros - e com graus de formalização e de estabilização dos objetos também diferentes.

Há, portanto, um ponto de vista comum a tais estudos, que paira sobre ou sob as diferenças, qual seja o de ocupar o "vão" entre pontos estáveis, o de preencher o espaço entre posições bem definidas pelos estudos lingüísticos anteriores - língua vs fala, competência vs performance, enunciação vs enunciado, lingüístico vs extralingüístico. Embaralham-se diferenças bem estabelecidas, mistura-se o que antes estava claramente separado, ou, como diz Guimarães Rosa, "tão claro como água suja". Os estudos do texto e do discurso, em decorrência, caracterizam-se pela fragilidade e instabilidade de não serem "nem isto, nem aquilo" ou de serem ao mesmo tempo "isto e aquilo".

A "fragilidade" dos estudos do texto e do discurso favorece assim críticas e objeções diversas, conforme a teoria se aproxime de um ou de outro pólo ou se mantenha em indecisa posição. Uma da objeções, em geral dita humanista, que sofrem as teorias do discurso é a de reducionismo. Essa objeção se refere ao "empobrecimento" que as teorias do discurso e do texto trazem a seu objeto de estudo, por excessivo formalismo, por adoção de um ponto teórico único, por muita preocupação com procedimentos lingüísticos e discursivos, 
em detrimento de outros aspectos mais "intuitivos" ou "criativos", por fazerem do texto o lugar apenas de comprovação ou de exemplificação de complicadas elaborações teóricas. Uma segunda objeção, também bastante freqüente, é a crítica ideológica de negação da história, feita a propostas como as de Benveniste, de Greimas, das pragmáti-cas em geral que, por considerarem apenas a enunciação pressuposta no discurso, nem sempre examinam devidamente as variáveis sócio-históricas que, com as lingüísticas, engendram os sentidos do discurso. A terceira critica seria o desafio "fundamentalista" (no dizer de Eric Landowski) de projetos mais descritivos que explicativos.

Em resumo, os estudos do texto e do discurso, por um lado, não são suficientemente formais e explicativos para a lingüística "hard", por outro são excessivamente formais ou estruturalistas ou atados a mecanismos internos para os adeptos de analises mais livres e "criativas". Embora sejam estudos da linguagem, os do discurso e do texto são muitas vezes marginalizados, porque caracterizados pela instabilidade aci-ma mencionada. Os que assim pensam não percebem que essa instabilida-de é condição do estudo da linguagem.

Em relação às críticas de reducionismo, cabe um "mea culpa" e uma defesa. É necessário reconhecer que são muitos os que se dizem estudiosos do texto sem o serem, muitos os que utilizam uma metalinguagem que desconhecem, muitos os que fazem realmente do texto um exemplo para teori-as mal digeridas. No entanto, é fácil separar o joio do trigo e, se nem sempre se faz a distinção, é porque interferem questões de outra ordem: o desco-nhecimento dos estudos do texto e do discurso, de seus avanços e resulta-dos, a má-fé e o medo de perder espaços.

A posição de instabilidade em que tais estudos colocam a linguagem é, portanto, a maior perdição deles e também sua maior "grandeza". O momento hoje é, sem dúvida, o de uma lingüística da instabilidade (veja-se, a respeito, José Luiz Fiorin em "Linguiística: perspectivas e aplicações", 1994). São os fatos lingüísticos instáveis, aqueles que não se resolvem como "ou isto ou aquilo", que instigam os estudiosos da linguagem, e os do discurso e do texto, antes de todos. $\mathrm{O}$ estudioso do discurso, bravamente, acredita poder dizer alguma coisa sobre essas questões, sem, no entanto, estabilizar o instável, pois cria apenas, e o reconhece, um equilíbrio precário.

2. Os estudos do texto e do discurso no Brasil.

2.1. Direções teóricas e distribuição no País 
Procurei apontar as características gerais e o ponto de vista comum dos estudos do texto e do discurso. Faço agora o caminho inverso e trato de ressaltar a enorme diversidade desses estudos, a partir da trilha comum examinada. Vou-me limitar a mencionar as grandes linhas dessas abordagens no Brasil, diferenciando-as segundo as perspectivas da filiação teórica e dos papéis que assumiram no País.

Para esse panorama geral e um tanto superficial foram utilizados dois tipos de dados: as linhas e projetos de pesquisa dos cursos de pós-graduação no Brasil, na área de Letras e Lingüística em 1990-1991 e 1994-1995 (material que me foi fornecido pela CAPES - Fundação Coordenação de Pessoal de Nível Superior); as informações do Quem é quem na pesquisa em Letras e Lingüística no Brasil (Marcuschi, 1992), publicado pela ANPOLL - Associação Nacional de Pesquisa e Pós-Graduação em Letras e Lingüística.

Com esses elementos, posso, de alguma forma, apontar os núcleos já constituídos e mais produtivos dos estudos do discurso no Brasil, os temas dos principais projetos em desenvolvimento e as direções teóricas dessas pesquisas.

Sete linhas teóricas destacam-se nos estudos do texto e do discurso no País: a Análise do Discurso (AD) francesa, a Semiótica Narrativa e Discursiva, também iniciada na França, as várias teorias do discurso inglesas, os estudos funcionalistas do discurso, a Lingüística Textual, sobretudo anglo-saxônica, a Análise da Conversação e/ou análises da organização textual/interativa do discurso, e uma última direção que reúne, de modo mais eclético, estudos que dialogam com a Teoria da Literatura, a Semiologia, a Pragmática e a Semântica, Bakhtin ou Benveniste. Há muitas outras que deixo de examinar por terem tido menor alcance no Brasil. É o caso, por exemplo, da proposta modular de Eddy Roulet, trabalhada sobretudo na Universidade Federal de Minas Gerais, em Belo Horizonte. Das sete direções teóricas destacadas, os estudos funcionalistas do discurso e a Lingüística Textual são objeto de reflexão de outros artigos deste número da revista.

A distribuição das cinco linhas restantes por universidades e por cursos de pós-graduação (há mais de 50 cursos de mestrado e de doutorado em Letras e Lingüística no Brasil) mostra aproximadamente o quadro que segue.

2.1.1. Análise do Discurso francesa (AD).

A Análise do Discurso $(\mathrm{AD})$ de linha francesa tem seus principais núcleos 
na Universidade Estadual de Campinas - UNICAMP, nos Departamentos de Linguiística e de Lingüística Aplicada. Desenvolvem-se lá grandes projetos coletivos e individuais, e boa parte dos analistas de discurso que hoje ensinam e formam pesquisadores nessa linha de investigação formou-se na UNICAMP. Há outros grupos menores, na Universidade de São Paulo - USP, sobretudo na pós-graduação em Língua Portuguesa, na Pontifícia Universidade Católica PUC, em São Paulo, no Rio Grande do Sul e no Rio de Janeiro, nas universidades federais do Rio Grande do Sul - UFRGS e Fluminense - UFF, além de iniciativas mais individuais de estudiosos espalhados por várias outras universidades federais (na Paraíba, no Mato Grosso, em Santa Catarina, em Alagoas, em Brasília, em Juiz de Fora).

Muitas das pesquisas sobre o discurso desenvolvidas no Brasil pertencem a essa linha de investigação e podem ser agrupadas em três grandes blocos: o primeiro, com pesquisas sobre questões teóricas que tradicionalmente preocupam os analistas do discurso e que receberam entre nós desenvolvimentos próprios, tais como os estudos sobre o sujeito, a autoria, a interpretação e o sentido, o discurso e o acontecimento, a heterogeneidade discursiva, a noção de arquivo (Universidade Estadual de Campinas UNICAMP, Universidade Federal do Rio Grande do Sul - UFGRS), ou as preocupações com a metodologia de análise do discurso (Universidade Estadual de Campinas - UNICAMP, Universidade Federal de Alagoas - UFAL); o segundo, com trabalhos também teóricos sobre discursos específicos ou sobre aspectos pontuais dos discursos, como por exemplo o discurso dos missionários (Universidade de São Paulo - USP e Universidade Estadual de Campinas - UNICAMP), da imigração (Universidade Estadual de Campinas UNICAMP), do humor (Universidade Estadual de Campinas - UNICAMP), da gramática (Universidade de São Paulo - USP e Universidade Estadual de Campinas - UNICAMP), o discurso político, religioso e jurídico (universidades federais de Alagoas - UFAL, do Rio Grande do Sul - UFRGS, Pontifícia Universidade Católica do Rio de Janeiro - PUC-RJ, Universidade Estadual de Campinas - UNICAMP), o discurso pedagógico (Universidade Estadual de Campinas - UNICAMP e Pontifícia Universidade Católica do Rio Grande do Sul - PUC/RS), o discurso naturalista (Universidade Estadual de Campinas UNICAMP), o funcionamento discursivo da disjunção em português (Universidade Estadual de Campinas - UNICAMP), a norma culta na perspectiva da análise do discurso (Universidade Federal do Rio Grande do Sul - UFRGS); o terceiro, com estudos sobre a realidade brasileira, enquanto discursos, entre os quais cito apenas os projetos sobre discurso, significação e brasilidade (Universidade Estadual de Campinas - UNICAMP), o discurso 
público no espaço urbano (Universidade Estadual de Campinas - UNICAMP), aspectos discursivos da análise de línguas indígenas (Universidade Estadual de Campinas - UNICAMP), os discursos missionários e literários sobre os índios e brasilidade (Universidade Estadual de Campinas - UNICAMP), o discurso público no espaço urbano (Universidade Estadual de Campinas UNICAMP), aspectos discursivos da análise de línguas indígenas (Universidade Estadual de Campinas - UNICAMP), os discursos missionários e literários sobre os índios (Universidade de São Paulo - USP), a História das Idéias Lingüísticas no Brasil (Universidade Estadual de Campinas - UNICAMP, Universidade de São Paulo - USP, Universidade Federal do Rio Grande do Sul - UFGRS, Universidade Federal Fluminense - UFF), o discurso do e sobre os sem-terra (Universidade Estadual de Campinas - UNICAMP e Universidade Federal de Alagoas - UFAL), as formações discursivas dos docentes da rede pública de Porto Alegre (Universidade Federal do Rio Grande do Sul - UFGRS).

\subsubsection{A influência dos ingleses nos estudos do discurso.}

Alguns indiretamente vinculados à Análise do Discurso de linha francesa, outros nem tanto, há grupos no Brasil que se relacionam mais de perto com as pesquisas dos ingleses sobre o discurso (Fairclough, Clark, Coulthard, Sinclair e outros). É o caso de estudiosos da Universidade de Brasília - UnB que examinam, por exemplo, o discurso e a interação em contextos institucionais, ou as interações médico-paciente, terapeuta-paciente e da Universidade Federal de Santa Catarina - UFSC, sobretudo na pós-graduação em inglês, que se voltam para questões de discurso e sexo, discurso jurídico, interação verbal e não-verbal, discursos de auto-ajuda.

2.1.3. Estudos dos textos orais: perspectivas textual-interativa e/ou conversacional.

Os estudos dos textos orais no Brasil têm-se efetuado sobretudo nas perspectivas textual-interativa e/ou conversacional da Análise da Conversação, da Sociolingüística Interacional, da Etnografia da Comunicação ou da Etnometodologia. Nessas direções estão envolvidos principalmente grupos localizados na Universidade de São Paulo - USP, nos cursos de Lingüística, de Língua Portuguesa e de Alemão, sobretudo, com o Projeto de Estudo da Norma Lingüística Urbana Culta de São Paulo - Projeto NURC-SPUSP, na Universidade de Campinas - UNICAMP, nos departamentos de Lingüística e de Lingüística Aplicada, na Universidade Federal de Pernambuco - UFPE, na Universidade Federal do Rio de Janeiro - UFRJ, na Universidade 
Estadual Paulista - UNESP, em Araraquara e em Assis, na Universidade Federal Fluminense - UFF e na Pontifícia Universidade Católica - PUC, em São Paulo e no Rio de Janeiro. Além dos grupos constituídos, há pesquisadores distribuídos em diferentes universidades do País (nas universidades federais do Paraná - UFPR, de Santa Catarina - UFSC, de Mato Grosso - UFMT, do Rio Grande do Norte - UFRN, do Pará - UFPA, de Minas Gerais - UFMG, do Rio Grande do Sul - UFRGS, de Brasília - UNB, da Bahia - UFBA, de Uberlândia UFU, de Alagoas - UFAL, Fluminense - UFF e na Universidade de Passo Fundo). Os estudiosos dos discursos orais aparecem, nas diferentes fontes consultadas, sob os rótulos de etnografia da comunicação, interação verbal, fala e escrita, estudo da fala, português falado e, principalmente, análise da conversação.

Os estudos dos núcleos estabelecidos ou dos pesquisadores isolados tratam sobretudo da organização textual-interativa da fala e dos procedimentos de construção dos discursos orais - estruturas paralelas, repetição, tópico, turnos, paráfrase, correção, hesitação, inserções, marcadores, rituais conversacionais - além de questões mais específicas sobre o poder na interação (na Universidade Federal de Pernambuco - UFPE), linguagem, interação e sexo (nas universidades federais de Pernambuco - UFPE e de Santa Catarina UFSC, e na Pontifícia Universidade Católica do Rio de Janeiro - PUC/RJ), interação no trabalho e em contextos institucionalizados - escola, empresa, mídia - (na Pontifícia Universidade Católica - PUC, em São Paulo e no Rio de Janeiro, nas universidades federais de Brasília - UNB, de Uberlândia - UFU e do Rio de Janeiro - UFRJ), relação entre fala e escrita (nas universidades federais de Pernambuco - UFPE, do Rio Grande do Norte - UFRN, de Uberlândia - UFU e na Universidade de São Paulo - USP), interação via computador, interação no discurso jurídico (na Universidade Federal de Juiz de Fora UFJF), linguagem dos idosos (na Universidade de São Paulo - USP), estratégias conversacionais no discurso psicótico (na Universidade Federal do Rio de Janeiro - UFRJ).

Dois grandes projetos estão em andamento sobre o português falado: o Projeto de Estudo da Norma Lingüística Urbana Culta, principalmente em São Paulo (Universidade de São Paulo - USP e Universidade Estadual de Campinas - UNICAMP), na Bahia (Universidade Federal da Bahia - UFBA, em Salvador), em Pernambuco (Universidade Federal de Pernambuco - UFPE, em Recife) e no Rio de Janeiro (Universidade Federal do Rio de Janeiro - UFRJ); o Projeto da Gramática do Português Falado, que envolve pesquisadores das diferentes instituições brasileiras e está centralizado na UNICAMP. Em ambos os projetos, 
os estudos do português falado não contemplam apenas as questões discursivas, textuais ou interativas da fala, mas alguns dos grupos envolvidos nesses projetos dedicam-se especificamente a tais aspectos, daí terem sido inseridos neste panorama da análise do discurso no Brasil.

O discurso oral e o português falado estão sendo examinados no Brasil com regularidade nos últimos vinte anos, de perspectivas teóricas muito diversas. Além das já mencionadas, análises interativas e conversacionais, que interessam diretamente a esta apresentação, podem ser citadas a lingüística textual, sobretudo, quando relacionada com os estudos cognitivos, com o processamento lingüístico cognitivo do texto oral, (Universidade Estadual de Campinas - UNICAMP, universidades federais Fluminense - UFF, Pontifícia Universidade Católica do Rio de Janeiro - PUC/Rio), algumas teorias semiolingüísticas (em geral na Pontifícia Universidade Católica - PUC, em São Paulo e no Rio e na Universidade Estadual do Rio de Janeiro - UERJ), os estudos sociolinguiísticos da variação e da interação, estreitamente relacionados com os do discurso oral ou da conversação, e que já apresentaram resultados significativos sobretudo nas universidades federais do Rio de Janeiro - UFRJ, de Santa Catarina - UFSC e do Paraná - UFPR e na Universidade Estadual do Rio de Janeiro - UERJ, além das demais teorias do discurso, tais como a Análise do Discurso francesa e a Semiótica, quando examinam os discursos orais.

\subsubsection{Semiótica narrativa e discursiva.}

O quarto bloco de estudos do discurso contempla os que têm como fundamentação teórica a Semiótica narrativa e discursiva, desenvolvida na França, por A. J. Greimas e por um grupo de pesquisadores principalmente na Escola de Altos Estudos em Ciências Sociais em Paris. Existem outras teorias semióticas, como a de Peirce ou a Escola de Tartu, por exemplo, também bastante conhecidas e produtivas no Brasil, mas que nem sempre podem ser consideradas teorias do discurso.

Por ser essa teoria a opção que fiz para os meus estudos sobre o discurso, posso apresentá-la com mais detalhes que os obtidos nas fontes consultadas.

A linha de investigação semiótica tem seus principais e mais antigos núcleos em São Paulo, na Universidade de São Paulo - USP, sobretudo na pósgraduação em Lingüística e na Escola de Comunicações e Artes - ECA, e na Universidade Estadual Paulista - UNESP, em Araraquara e em São José do Rio 
Preto. Nessas universidades formou-se a maioria dos pesquisadores em Semiótica no Brasil e desenvolveu-se grande parte dos projetos de pesquisa na área. Em 1973, constituiu-se, com pesquisadores dessas instituições, um Centro de Estudos Semióticos que teve papel inegável na formação de pesquisadores e na divulgação dessa linha de pesquisa. Há atualmente outros grupos que merecem destaque, na PUC-SP (com um Centro de Estudos Sociossemióticos muito ativo), nas universidades federais do Rio Grande do Sul - UFRGS, de Minas Gerais - UFMG e Fluminense - UFF, na Universidade Estadual Paulista - UNESP, em Assis e na Universidade de Londrina - UEL. Alguns desses núcleos não estão ligados diretamente aos estudos lingüísticos, em sentido restrito, o que permite o enriquecimento dos estudos dos discursos verbais, orais e escritos, que podem assim ser aproximados, com um mesmo ponto de vista teórico, dos discursos do cinema, da publicidade, da pintura, etc.

A semiótica no Brasil tem cumprido, a seu modo e com suas possibilidades teóricas e metodológicas, os papéis e funções dos estudos do discurso em geral. Os semioticistas não se descuidaram das questões teóricas e, atualmente, três direções têm sido empreendidas no Brasil. A primeira sobre a sintaxe e a semântica do discurso, com estudos que examinam principalmente as estratégias do discurso - ambigüidade discursiva, argumentação, figurativização, aspectualização, configurações patêmicas - e as relações entre enunciação e discurso. Essas pesquisas preocupam-se também com a descrição do português. A segunda direção congrega estudos que revêem a concepção e organização do nível fundamental dos discursos, a partir de estudos sobre a figuratividade e a tensividade do esquema profundo. A terceira, diz respeito aos estudos de uma semiótica específica - discursos visuais, gustativos, poéticos, estéticos, da canção popular, da música, da pintura, do cinema -, às traduções intersemióticas e aos estudos interdisciplinares - semiótica e psicanálise, semiótica e teoria das catástrofes, semiótica e estudos cognitivos, semiótica e análise da conversação, semiótica e retórica. Examina-se, nesse bloco de pesquisas, o plano da expressão dos textos, do ponto de vista da construção do sentido, ou seja, estudam-se questões de sincretismo de expressão, de especificidade de certas matérias e substâncias da expressão, de relação semi-simbólica ou tensiva entre expressão e conteúdo.

Entre os projetos de pesquisa mais "aplicados" ou "sociais" da semiótica, menciono apenas alguns sobre os discursos dos presidentes militares após 64, a canção popular brasileira, os discursos dos livros didáticos de História do Brasil, a história das idéias lingüísticas no País, o discurso do vestibulando, 
o discurso separatista gaúcho, os discursos literários brasileiros, o discurso da crítica de arte no Brasil.

\subsubsection{Outros.}

O último grupo reúne as pesquisas que combinam perspectivas diversas de análise do discurso e do texto e que são encontradas em quase todos os centros de pesquisa do País. Cito alguns deles:

a) estudos a partir de ou em torno dos escritos de Bakhtin, e, sobretudo, das questões de dialogismo, polifonia, intertextualidade, heterogeneidade discursiva, metalinguagem, paráfrase, ironia, humor, tanto em exames lingüísticos quanto literários, desenvolvidos principalmente na Universidade de São Paulo - USP, na Universidade Federal do Paraná - UFPR e na Pontifícia Universidade Católica - PUC, em São Paulo (Há pesquisadores individuais em outras universidades, tais como as universidades federais de Santa Maria UFSM, de Minas Gerais - UFMG e de Juiz de Fora - UFJF);

b) estudos do discurso nas várias perspectivas pragmáticas, semânticas ou enunciativas (Benveniste, Jakobson e outros) e com materiais e objetivos também diversificados, tais como os provérbios, as fábulas, o discurso totalitário, o discurso jornalístico, a nação brasileira, a metáfora, o paratexto (prefácio), o texto publicitário, metáforas na TV, desenvolvidos sobretudo na Universidade de São Paulo - USP (em diferentes programas de pós-graduação), na Universidade de Campinas - UNICAMP, na Universidade Estadual Paulista - UNESP, em Araraquara, nas universidades federais do Rio Grande do Sul UFRGS, de Pernambuco - UFPE, de Santa Catarina - UFSC, do Rio de Janeiro - UFRJ, do Ceará - UFCE, de Minas Gerais - UFMG e Fluminense - UFF e na Pontíficia Universidade Católica - PUC, no Rio de Janeiro e em São Paulo (Observe-se que no Quem é quem há grande intersecção entre os pesquisadores que se colocaram sob as etiquetas "pragmática", "semântica" e "análise do discurso");

c) estudos do discurso nos cursos de literatura das universidades brasileiras, em que, às pesquisas que examinam os discursos poéticos, estéticos ou literários (narrativa literária, discurso memorialista, biográfico, epistolar, ensaio, intertextualidade) com as fundamentações teóricas já mencionadas (análise do discurso francesa, lingüística textual, semiótica, etc), somam-se estudos com base na estética da recepção (nas universidade federais de Minas Gerais - UFMG, de Santa Catarina - UFSC, na Universidade de São Paulo - 
USP, na Pontifícia Universidade Católica - PUC, do Rio de Janeiro e de Minas Gerais, na Universidade Estadual de Londrina - UEL), na hermenêntica (na Universidade de Brasília - UNB), na retórica e na estilística (na Universidade de São Paulo - USP, nas universidades federais do Rio de Janeiro - UFRJ, da Paraíba - UFPB, do Rio Grande do Sul - UFRGS, da Bahia - UFBA e Fluminense - UFF, na Pontifícia Universidade Católica de São Paulo - PUC-SP, na Universidade de Brasília - UNB,), na crítica genética (na Universidade de São Paulo - USP, nas universidades federais da Paraíba - UFPB e de Santa Catarina - UFSC), na semiologia (na Universidade Federal do Rio de Janeiro - UFRJ), com projetos, entre outros, sobre o discurso feminino ou sobre a mulher na literatura (nas universidades federais de Minas Gerais - UFMG, do Pará UFPA, do Rio Grande do Norte - UFRN, de Alagoas - UFAL, do Rio de Janeiro - UFRJ, do Rio Grande do Sul - UFRGS, do Espírito Santo - UFES e Fluminense - UFF, na Universidade Estadual do Rio de Janeiro - UERJ, na Pontifícia Universidade Católica - PUC, em Minas Gerais, em São Paulo e no Rio de Janeiro, na Universidade de São Paulo - USP), sobre a oralidade e a escrita na literatura (nas universidades federais de Minas Gerais - UFMG, da Bahia UFBA, da Paraíba - UFPB, na Universidade Estadual Paulista - UNESP, em São José do Rio Preto), sobre leitura e literatura, sobre a formação de leitores, sobre o ensino da literatura ou sobre literatura e educação (na Universidade Estadual Paulista - UNESP, em Assis, na Universidade de São Paulo - USP, nas universidades federais do Rio de Janeiro - UFRJ, do Rio Grande do Norte UFRN, de Minas Gerais - UFMG, de Brasília - UNB, na Pontifícia Universidade Católica do Rio de Janeiro - PUC/RJ, na Universidade Estadual de Londrina UEL), sobre música e literatura (na Universidade Federal do Paraná - UFPR, na Universidade de São Paulo - USP, na Pontifícia Universidade Católica do Rio de Janeiro - PUC/RJ, na Universidade Federal do Rio de Janeiro - UFRJ), sobre pintura, arquitetura ou artes visuais, em geral, e literatura (na Universidade de Brasília - UNB, na Universidade de São Paulo - USP, na Universidade Estadual Paulista - UNESP, em São José do Rio Preto e em Araraquara, na Pontifícia Universidade Católica do Rio de Janeiro - PUC/RJ, nas universidade federais de Minas Gerais - UFMG, do Rio de Janeiro - UFRJ e de Juiz de Fora - UFJF), sobre literatura e jornalismo ou literatura e mídias (na Universidade de São Paulo - USP, na Universidade Federal da Bahia - UFBA), sobre mito (Universidade de Brasília - UNB), sobre humor na literatura (na Universidade Estadual de Campinas - UNICAMP, na Universidade Federal do Espírito Santo - UFES, na Pontifícia Universidade Católica de Minas Gerais - PUC/MG) e, com muita frequiência, sobre o discurso da crítica, da teoria literária, das revistas culturais (nas universidades federais da Bahia - UFBA e do Rio de Janeiro UFRJ, na Pontifícia Universidade Católica - PUC, no Rio de Janeiro, na 
Universidade Estadual do Rio de Janeiro - UERJ, na Universidade de São Paulo - USP);

d) estudos semiológicos e semiolingüísticos do discurso, de inspiração francesa, localizados principalmente nas universidades do Rio de Janeiro (UFRJ, UFF, UERJ, PUC), nas universidades federais de Minas Gerais - UFMG e de Juiz de Fora - UFJF, na Pontifícia Universidade Católica de São Paulo - PUC/ SP, na Universidade Estadual Paulista - UNESP, em São José do Rio Preto;

e) estudos filológicos que, muitas vezes, se aproximam das análises do discurso e do texto, tal como previam R. Jakobson (Essais de Lingüístique Générale; p. 21) e Isaac Nicolau Salum, com suas análises em "garfos", e que podem ser encontrados hoje sobretudo na Pontifícia Universidade Católica de Minas Gerais - PUC/MG, nas universidades federais da Bahia - UFBA, da Paraíba - UFPB, do Rio de Janeiro - UFRJ e Fluminense - UFF e na Universidade de São Paulo - USP.

Finalmente, menciono rapidamente o estreito relacionamento que as análises do discurso mantêm com outras disciplinas ou campos do conhecimento. Faço referência apenas às relações interdisciplinares mais usuais no Brasil:

- com a fonética e a fonologia, e em direções teóricas diversas dos estudos do discurso, principalmente na Universidade Estadual de Campinas UNICAMP e na Universidade Estadual Paulista - UNESP, em Marília;

- com a linguística indígena, sobretudo na linha da análise do discurso francesa e com estudos sobre aspectos discursivos das línguas indígenas, sobre o discurso missionário e sobre questões de ensino/aprendizagem, desenvolvidos principalmente na Universidade de Campinas - UNICAMP, na Universidade de São Paulo - USP e na Universidade Federal de Goiás - UFGO;

- com a neurolingüística, principalmente na Universidade Estadual de Campinas - UNICAMP;

- com os estudos de aquisição de linguagem, em diversas direções teóricas da análise do discurso, mas em geral nas dos estudos cognitivos do texto e dos estudos discursivos de língua falada, principalmente na Universidade Estadual de Campinas - UNICAMP, na Universidade Federal de Santa Catarina - UFSC e na Universidade Estadual Paulista - UNESP, em Araraquara.

- com a informática, em que se desenvolvem metodologias para análise de discursos, sobretudo na Universidade de São Paulo - USP, na Pontifícia Universidade Católica - PUC de São Paulo e do Rio de Janeiro e na Universidade Federal de Santa Catarina - UFSC; 
- com a psicanálise, em diferentes direções dos estudos do discurso, mas principalmente na análise do discurso francesa, na semiótica, na sociolingüística interacional, na análise da conversação e na língüística textual, na Universidade de São Paulo - USP, na Universidade Estadual de Campinas - UNICAMP e na Universidade Federal do Rio de Janeiro - UFRJ (Há muitos outros estudos no Brasil que aproximam psicanálise e estudos do texto, mas, a maioria, no campo da literatura, como por exemplo nas universidades federais de Alagoas - UFAL, de Minas Gerais - UFMG, do Rio de Janeiro - UFRJ, de Juiz de Fora - UFJF e na Pontifícia Universidade Católica de Minas Gerais - PUC/MG);

- com a sociolingüística e a teoria da variação, sobretudo nas universidades federais do Rio de Janeiro - UFRJ, de Santa Catarina - UFSC, do Paraná - UFPR e Fluminense - UFF e na Pontifícia Universidade Católica do Rio de Janeiro - PUC/RJ;

- com a sintaxe ou a teoria da gramática, no caso, essencialmente, dos estudos funcionalistas do discurso, nas universidades federais de Santa Catarina - UFSC, do Rio de Janeiro - UFRJ, Fluminense - UFF e de Juiz de Fora UFJF, na Universidade de São Paulo - USP e na Universidade Estadual Paulista - UNESP, em Araraquara;

- com a lingüística aplicada, laços que serão examinados na última parte deste texto.

3. Papéis e funções dos estudos do texto e do discurso no Brasil.

As funções primeiras dos estudos do texto e do discurso são, sem dúvida, as do estudos lingüísticos em geral: a de contribuir para o conhecimento da linguagem, através da língua e de seus discursos e, pela linguagem, do homem; a de concorrer para o desenvolvimento teórico e metodológico da própria disciplina. Com esses fins, os estudiosos do discurso no Brasil têm realizado pesquisas nas várias direções já apontadas neste artigo e conforme a perspectiva teórica escolhida. $\mathrm{O}$ acúmulo de conhecimento já é grande e sabese hoje bem mais sobre o discurso do que se sabia há trinta anos.

Além das preocupações teóricas, os estudos do texto e do discurso têm papéis que poderiam ser ditos "sociais", não fosse a redundância do termo, nesse campo do conhecimento: o de participar dos debates sobre ensino/ aprendizagem da competência discursiva, em língua materna e em segunda língua; o de contribuir para que se conheçam melhor, por meio dos discursos, a cultura e a sociedade brasileiras.

\subsection{Questões de ensino.}


Os estudos do discurso são imprescindíveis para o ensino/aprendizagem da competência discursiva e os pesquisadores brasileiros não se furtaram a essa tarefa. Sem dúvida, outros caminhos têm sido também empreendidos, com êxito, nesse campo. Somam-se esforços, conjugam-se pesquisas, comparam-se resultados. Poucos são os estudiosos do texto e do discurso que, enquanto tal, não se dedicam ou tenham-se dedicado a questões de ensino, em três grupos de preocupações: leitura, redação, escrita e tradução; ensino/aprendizagem de língua materna e estrangeira; interação, sala de aula, relação professor/aluno.

Os laços são, portanto, estreitos com a lingüística aplicada, embora haja diferenças teóricas e de métodos entre a lingüística aplicada e os estudos do discurso. Menciono alguns centros em que essa interação ocorre, em geral nos cursos de línguas estrangeiras, além é claro, dos de lingüística aplicada, e com diferentes perspectivas dos estudos do discurso:

- problemas de tradução, nas universidades federais de Santa Catarina UFSC (sobretudo na pós-graduação em inglês), de Brasília - UnB, do Rio Grande do Sul - UFRGS, de Santa Maria - UFSM, do Rio de Janeiro - UFRJ, de Minas Gerais - UFMG, de Uberlândia - UFU e Fluminense - UFF, na Universidade Estadual de Campinas - UNICAMP, na Universidade de São Paulo- USP, na Universidade Estadual Paulista - UNESP, em Assis (Podem ser incluídas nesse grupo as preocupações com a tradução literária ou poética, muito freqüentes nos cursos de literatura de diferentes universidades Universidade Federal da Paraíba - UFPB, Universidade de Brasília - UnB, Universidade de São Paulo - USP);

- redação, leitura, compreensão, na Universidade Estadual Paulista UNESP, em São José do Rio Preto e em Araraquara, na Universidade Estadual de Campinas - UNICAMP, na Universidade de São Paulo - USP, nas universidades federais de Alagoas - UFAL, da Bahia - UFBA, da Paraíba UFPB, de Pernambuco - UFPE, do Rio de Janeiro - UFRJ, de Santa Catarina UFSC, de Minas Gerais - UFMG, do Paraná - UFPR, do Pará - UFPA, do Rio Grande do Sul - UFRGS, de Santa Maria - UFSM, de Uberlândia - UFU, Fluminense - UFF, na Pontifícia Universidade Católica - PUC, em São Paulo e no Rio Grande do Sul;

- ensino de línguas indígenas e interações transculturais na Universidade Federal de Goiânia - UFGO e na Universidade Estadual de Campinas UNICAMP;

- interação na escola, professor/aluno em sala de aula, em que a aula é vista como um discurso, na Universidade de Campinas - UNICAMP, nas 
universidades federais de Brasília - UnB, de Pernambuco - UFPE, do Rio Grande do Norte - UFRN, de Alagoas - UFAL, na Universidade de São Paulo - USP, na Pontifícia Universidade Católica de São Paulo - PUC/SP;

- análise do discurso e o ensino de $1^{\mathrm{a}}$ e $2^{\mathrm{a}}$ línguas, na Universidade Estadual de Campinas - UNICAMP, nas universidades federais de Santa Catarina - UFSC, do Rio de Janeiro - UFRJ e de Minas Gerais, UFMG, na Universidade de São Paulo - USP, na Universidade Estadual Paulista - UNESP, em Assis e Araraquara;

- processos discursivos na educação, na Universidade de Brasília - UnB, na Universidade de Campinas - UNICAMP, na Universidade de São Paulo USP, na Universidade Federal de Pernambuco - UFPE, na Pontifícia Universidade Católica de São Paulo - PUC/SP, na Universidade Estadual do Rio de Janeiro UERJ;

- discurso pedagógico, nas universidades federais do Rio Grande do Norte - UFRN, na Pontifícia Universidade Católica do Rio Grande do Sul PUC/RS, na Universidade Estadual de Campinas - UNICAMP, na Universidade de São Paulo - USP;

- discurso do livro didático, Universidade de São Paulo - USP, universidades federais da Paraíba - UFPB, de Universidade Estadual Paulista - UNESP, em Araraquara, na Universidade Estadual de Londrina - UEL, na Universidade Estadual de Campinas - UNICAMP

\subsection{Discurso e sociedade.}

As investigações sobre o discurso que têm por preocupação contribuir para que se conheça melhor, por meio da linguagem, a sociedade brasileira são bastante numerosas no Brasil. É fácil perceber nas pesquisas que foram já citadas neste artigo o interesse que os estudiosos brasileiros do discurso, das diversas perspectivas, têm por esse tipo de pesquisa. São estudos sobre a História das idéias lingüísticas no Brasil (UNICAMP e USP); o discurso no espaço urbano (UNICAMP); discurso significação e brasilidade (UNICAMP); discurso político e religioso - dos presidentes da ditadura, de Antônio Conselheiro, separatista, etc - (USP, UNICAMP, UFRGS); o discurso nas situações de trabalho no Brasil e em relação ao Mercosul (UFRGS, UNICAMP, PUC/SP, PUC/Rio); o discurso urbano oral culto no Brasil (USP, UNICAMP, UFBA, UFPE, UFRJ); os livros didáticos, as redações de vestibular (USP, UNICAMP, PUC/SP); o discurso dos livros didáticos da História do Brasil (USP); o discurso dos missionários (UNICAMP, USP); os discursos dos índios (UNICAMP, UFGO), a construção discursiva dos heróis nacionais (USP); o discurso dos adolescentes e dos idosos brasileiros (USP, UFMG); as canções 
populares brasileiras (USP); os discursos literários no Brasil (em diferentes universidades); o discurso da crítica de arte no Brasil (UFF), a argumentação nos editoriais de jornais de grande circulação (UFRGS); o discurso humorístico (UNICAMP); a fala e a escrita da mulher no Brasil (UFPE, UFF, UFRN); o discurso jurídico brasileiro (PUC-SP, UNISINOS) e muitos outros.

Deve-se mencionar que, desses estudos completados ou em andamento, desenvolvidos como projetos coletivos ou individuais, com a participação de pesquisadores experimentados, de alunos e de pós-graduandos, resultaram e resultam um número expressivo de teses, dissertações, livros, capítulos de livros, ensaios, artigos em revistas especializadas. Se os estudiosos do discurso no Brasil têm procurado cumprir seus múltiplos papéis e dado uma pequena contribuição para que se aprimore o ensino, para que as teorias lingüísticas avancem e para que se conheça um pouco melhor a sociedade brasileira, há ainda muito a ser feito.

Espero ter conseguido, sem muitas distorções e com as fontes a que pude ter acesso, localizar os principais núcleos de exame do discurso no Brasil e, principalmente, mostrar o papel que desempenham entre nós e o estágio de desenvolvimento que alcançaram nas últimas décadas.

Termino expondo uma crença (ou uma certeza): a de que, tendo em vista o amadurecimento que se alcançou nessa área, é hora de deixar os esforços dos estudiosos do discurso na América Latina, para que se somem resultados e preocupações, dificuldades e soluções, caminhos comuns e perspectivas diversas.

\section{REFERÊNCIAS BIBLIOGRÁFICAS}

BARRos, D. L. P. de (1996) Reflexões sobre os estudos do texto e do discurso. Língua e Literatura, 22. São Paulo: 181-199.

FIORIN, J. L. (1994) Lingüística: perspectivas e aplicações. Estudos Lingüísticos. XXIII Anais de Seminários do GEL, I: 18-25.

Marcuschi, L. A. (org.) ( 1992) Quem é quem na pesquisa em Letras e Lingüística no Brasil. Associação Nacional de Pós-Graduação e Pesquisa em Letras e Lingüística - ANPOLL, Recife. 